\title{
Üniversite Öğrencilerinin Düşünce Hataları ve Duyguları iffade Etmelerinin Mükemmeliyetçilik Tutumlarını Yordaması ${ }^{*}$
}

\section{Thought Errors of the University Students and How Their Expressing Emotions Predict Their Perfectionism Attitude}

\author{
Ersoy ÇARKIT ** Süleyman Barbaros YALÇIN ***
}

\begin{abstract}
Öz. Bu çalışmanın amacı, üniversite öğrencilerinin duyguları ifade etme ve bilişsel hataları ile mükemmeliyetçilikleri arasındaki yordayıcı ilişkileri incelemektir. Araştırmanın verileri "Frost Çok Boyutlu Mükemmeliyetçilik Ölçeği", "Duyguları iffade Ölçeği" ve "Bilişsel Hatalar Ölçeği' ile toplanmıştır. Araştırma sonuçlarına göre olumlu duygu ifadesi, aile beklentileri ve yaptığından emin olamama ile pozitif yönde anlamlı ilişki içindeyken düzen boyutuyla ters yönlü anlamlı ilişki içerisindedir. Aynı zamanda yakınlık ifadesi, ailesel eleştiri ile negatif yönde anlamlı yönde ilişkili olduğu görülmektedir. Felaketleştirme, genelleme, kişiselleştirme ve seçici soyutlama ile mükemmeliyetçiliğin hata yapma endişesi, ailesel eleştiri ve yaptığından emin olamama boyutları pozitif yönde anlamlı yönde ilişkidir. Felaketleştirme, genelleme ve kişiselleştirme ile mükemmeliyetçiliğin aile beklentileri boyutunun pozitif yönde anlamlı ilişki yönde iliş̧ili olduğu bulunmuştur. Felaketleştirme ve kişiselleştirme ile kişisel standartlar alt boyutu pozitif yönde manidar ilişki içerisindedir.
\end{abstract}

Anahtar Kelimeler: Mükemmeliyetçilik, bilişsel hatalar, bilişsel çarpıtmalar, duyguları ifade etme.

\begin{abstract}
The purpose of this study is to examine whether or not cognitive errors and expressing emotions significantly predict the perfectionism of university students. "Frost's Multidimensional Perfectionism Scale", "Expressing Emotions Scale" and "Cognitive Errors Scale" were used to assess study constructs. Depending on the results of research, it has been found that expressing emotions has been positively related with family expectations and being not sure of what the oneself's doing, while it has been found that it is negatively related with the order dimension. Also, it has been found that closeness expression is negatively related with the parental critism. It has been found that catastrophizing, overgeneralizing, personalization and selective abstraction are positively related with the dimensions of perfectionism's concern of making mistakes, parental critism and being not sure of what the oneself's doing. It has been found that catastrophizing is positively related with the overgeneralization, personalization and the perfectionism's family expectations dimension. It has been found that catastrophizing and personalization are positively related with perfetionism's personal standarts dimension.
\end{abstract}

Keywords: Perfectionism, cognitive errors, cognitive distortions, expressing the emotions.

\begin{abstract}
Toplumsal Mesaj.
Üniversite

öğrencileri yaşamlarının ilerleyen dönemlerinde toplum içinde farklı görev ve statüde çalışırlar. $\mathrm{Bu}$ görevleri icra ederken bireyler mükemmeliyetçi oldukları zaman kendilerini baskı altında hissederler. Özellikle de düşünce hataları mükemmeliyetçiliklerini tetiklediği ve duygularını da ifade edemedikleri zaman potansiyellerini sergileyemezler. $\mathrm{Bu}$ nedenle de bu tip bireyler toplum için fayda sağlayamazlar. Bu bireyleri topluma daha yararlı hale getirmek için mükemmeliyetçiliklerini yordayan düşünce hatalarını tespit etmek bu düşünce hatalarının bireyde oluşturduğu olumsuzluğu gidermek adına önemli olabilir.
\end{abstract}

Public Interest Statement.

University students work in different tasks and status within the society in the later oncoming days of their life. While performing these tasks, individuals feel overwhelmed if they are perfectionists. They can not exhibit their potentials, in particular, when their thought mistakes trigger their perfectionism and they can not express their emotions. For this reason, such individuals can not be beneficial to society. In order to make these individuals more useful identifying the mistakes of their thinking way that collapse their perfectionism may be important in order to get rid of the negative consequences of these mistakes in the individual.

\footnotetext{
* Çalışma ikinci yazarın danışmanlığında tamamlanan birinci yazarın yüksek lisans tezinden üretilmiştir.

${ }^{*}$ Yrd. Doç. Dr., Necmettin Erbakan Üniversitesi, Eğitim Fakültesi, Rehberlik ve Psikolojik Danışmanlık Anabilim Dalı,

barbarosyalcin@konya.edu.tr

*** ersoy.12@hotmail.com

Çarkıt, E. ve Yalçın, S. B. (2018). Üniversite Öğrencilerinin Düşünce Hataları ve Duyguları Ifade Etmelerinin Mükemmeliyetçilik Tutumlarını Yordaması. Sakarya University Journal of Education, 8(1), 195-210.
} 


\section{GíRiş}

Birey, doğduğu andan itibaren çevresindeki birçok insanın geliştirme ve iyileştirme girişimleriyle karşı karşıya kalmaktadır. Yaşamın ilerleyen yıllarında da davranışlar sürekli ödüllendirilmeye ve eleştirilmeye devam edilir. İsteklerin karşılanmasına yönelik örüntü, yaşam boyu devam eder (Antony ve Swinson, 2000). Mükemmeliyetçiliğin gelişiminde, ebeveynlerin mükemmeliyetçi bir yapıya sahip olması ve çocuktan belli standartlara uyması beklenirken (Hamachek, 1978) bazı çocuklar fiziksel şiddete uğrayabilir ve bu şiddet durumlarına başlıca tepkiler geliştirirler. Bu şekilde çocuklar, geliştirme çabalarına mükemmeliyetçi olarak tepki gösterirler (Flett ve Hewitt, 2002). Mükemmeliyetçilik, bireyin kendine zorlayıcı standartlar belirlemesi, problem yaratmasına rağmen standartlara ulaşmak için aşırı çaba göstermesi ve özdeğerini yüksek standartlara dayandırarak öz eleştirel bir tutum sergilemesidir (Shafran, Egan ve Wade, 2010). Mükemmeliyetçi insan, hem duygularını açığa vurmayı reddederek, hem de kendisine bu duyguları yaşama fırsatı vermeyerek gerçek duygularını inkâr eder (Ben-Sharar, 2014). Bu bağlamda kendini aşırı eleştirel değerlendiren insanlar, kişisel sorunlarını gizleme eğilimi içerisindedir (Kawamura ve Frost, 2004; Frost, Trepanier, Brown, Heimberg, Juster, Makris ve Leung, 1997; Frost, Turcotte, Heimberg, Mattia, Holt ve Hope, 1995). Mükemmeliyetçi bireyler, duyguları düzenleme becerileri zayıf (Nyland, 2004; Bergman, Nyland ve Burns, 2007; Garrison, 2014; Aldea ve Rice, 2006), duygusal zeka seviyeleri düşük (Smith, Saklofske ve Nordstokle, 2014; Kaya, 2015), duygularını açma konusunda yetersiz (Garrison, 2014) ve kendini gizleme davranışı içerisinde (Kawamura ve Frost, 2004) olan kişiler olarak görülmektedir. Ayrıca Merrell, Hannah, Van Arsdale, Buman ve Rice (2011), kendini yazarak ifade etmek, direk ifade etmeye nazaran daha kolay olduğu için mükemeliyetçilerle bu şekilde çalışmanın daha faydalı olacağını belirtmişlerdir. Bu bakış açısı araştırmalarda mükemmeliyetçiliğin birçok faktör tarafından yordanabileceği görüşünü bizlere sunmaktadır. Bu aşamada mükemmeliyetçi bireylerin tutum ve davranışlarının yeterince anlaşılabilmesi için, duygularını ifade etme şekillerini incelemenin önemli bir yere sahip olduğu anlaşılmaktadır.

Duygular yaşamla birlikte başlar, yaşam boyu gelişir, zenginleşir. Günlük yaşam içerisinde insanlar, birçok farklı durumla karşılaşmakta ve bu durumlar karşısında farklı duygusal tepkilerde bulunmaktadırlar. Bu durum kişilik yapısına göre değişebilen doğal ve yaşam için gerekli olan durumlardır. Belli durumlar karşısında hiçbir duygusal tepki göstermeyen ya da belli kalıplarda tepkiler gösteren insanların psikolojik sıkıntılar yaşadığı düşünülmektedir (Köknel, 1997). Bireyin duygularının, oluşumu ve etkileri bakımından yaşamda çok değerli ve genelleyici yeri vardır. Bireylerin sosyal rolleri, üstlendikleri kimlikler hangi duyguların yaşanacağını, tavırlarının nasıl olacağını belirlemektedir (Öksüz, 2012). Duygular yaşamın tümünü etkileyebilecek yaşamın amacını, doyumunu ve anlamını oluşturacak özellik ve önemdedir. İnsan duygu ve düşünceleri fark edip anlamlandırarak, onları ifade etmesiyle ve iletişim kurabilme özelliğiyle diğer canlılardan ayrılmaktadır (Koçak, 2002). Duyguları ifade etme, kişinin yaşadığı olumlu ve olumsuz duyguları paylaşması olarak tanımlanmaktadır (King ve Emmons, 1990). Duyguların ifadesi, çığlık atma, ağlama, gülümseme, eşyaları etrafa fırlatma gibi çıkışları kapsar (Smyth, Pennebaker ve Arigo, 2001). Duyguları ayırt etmek ve ifade etmenin iletişimdeki yeri yadsınamaz bir gerçektir. Kişinin duygularını öz yansıtma süreci olarak dile aktarması, duygularını anlamlandırması ve denetim altına alması için en kestirme yoldur (Ergin, 2000). Duyguları fark etme ve duyguları ifade etmenin, psikolojik sağılı açısından önemli olduğu (Lundh, Johnsson, Sundqvist ve Olsson, 2002; Kuyumcu, 2012; Charry, Campell, Bydlowski, Chevallier ve Consoli, 2004), atılganlık düzeyi yüksek kişilerde duyguları ifade etmenin de yüksek olduğu (Dönmez, 2007), psikolojik yardım arama tutumunda duyguları ifade etmenin önemli bir yeri olduğu (Serim, 2011), öz duyarlık seviyesi yüksek kişilerin duyguları ifade etme düzeylerinin yüksek olduğu (Mete Otlu, ikiz ve Asıcı, 2016) görülmektedir.

Bireyin sahip olduğu mükemmeliyetçiliği etkileyen önemli bir değişkenin de kişinin sahip olduğu düşünce yapıları olduğu görülmektedir. Ellis (1987), mükemmeliyetçilikte genel kabul edilmiş olan inancın, yüksek beklentilerin temelindeki öz eleştiri olduğunu ve bunun bireyi bir takım problemlere yönlendirdiğini belirtmiştir. Ellis (2002), olanak dahilindeki tüm durumlarda başarılı ve yetkin olma düşüncesi, her şey istediği gibi olmadığı durumların sonucunu abartılı bir şekilde 
algılama eğilimi, problemlerin tam, net ve harika olan tek bir üstesinden gelme yönteminin olduğu düşüncesi doğrudan mükemmeliyetçilikle ilgilidir. Bilişsel yaşantılarımız, hayatın her alanında vazgeçilmez bir role sahiptir. Etraftaki uyaranlar ve bunlara verdiğimiz anlamlar, unuttuklarımız, hatırladıklarımız, kendimize ve çevremize ilişkin geliştirdiğimiz düşünce kalıpları, şemalar, çevreyle olan ilişkilerimizde önemli bir yere sahiptir (Dökmen, 2010). Bilişsel yapının en altında yer alan, erken çocukluk dönemindeki deneyimler ve içselleştirmeler sonucu oluşan, çaresizlik, sevilmeme ve değersizlik olarak üç kategaride toplanan çekirdek inançlar, insanların, şahsi ve sosyal bilgiyi nasıl yapılandıracağını belirleyen, bireyin kendisi, başkaları ve evrenle alakalı şemasal yapılardır (Beck, 2014; Sharf, 2014). Otomatik düşünceler ve temel inançlar arasında yeralan, kişinin dile getirmemekle birlikte inanmakta olduğu kurallar, sayıltılar ve tutumlar ise ara inançlarını oluşturmaktadır (Türkçapar, 2012). Bilişsel hatalar ise, fonksiyonel olmayan şemalar ile otomatik düşünceler arasında yer alır ve psikopatolojiye has çarpıklıklara neden olur. Alınan yeni bilgi bilişsel olarak sisteme girdiğinde, mevcut şemaya adaptasyon için çoğunlukla çarptırılır (Sharf, 2014; Türkçapar, 2012; Yalçın, Kavaklı, Kesici ve Ak, 2017). Bireylerin sahip olduğu bu bilişsel hataların depresyon, anksiyete, kişilik bozuklukları gibi durumlarda önemli rol oynadığı (Gönen, 2014; Batmaz, Koçbıyık ve Yunca, 2015; Kınık, 2015; Blake, Dobson, Sheptycki ve Drapeau, 2016; Wilson, Bushnell, Rickwood, Caputi ve Thomas, 2011) bilinmektedir. İki uçlu düşünme ile olumsuz mükemmeliyetçiliğin (Burns ve Fedawa, 2005; Egan, Piek, Dyck ve Rees, 2007), felaketleştirme ile kendine odaklı mükemmeliyetçiliğin (Flett, Hewitt ve Cheng, 2008) ve sosyal düzene yönelik mükemmeliyetçiliğin (Flett, Hewitt ve Rudolph, 2007) ilişkili olduğu görülmektedir. Çocukların sahip olduğu felaketleştirme, kişiselleştirme, genelleme ve seçici soyutlama bilişsel çarpıtmaları; hatalara karşı duyarlılı̆ı, kompulsif davranışları ve onaylanma ihtiyacını arttırmaktadır (Davis ve Wosinski, 2012). Ayrıca mantık dışı inançlar arttıkça mükemmeliyetçilik de artmaktadır (Yalçın, Kavaklı ve Kesici, 2017). Bu bağlamda mükemmeliyetçiliğin arkasında, kişinin sahip olduğu bilişsel hatalar açıkça görülmektedir. Bilişsel hatalar, mükemmeliyetçiliğin oluşturulması ve davranışların ortaya konulması açısından büyük önem arz eder.

Mükemmeliyetçi bireylerin kendilerine yönelik farkındalık kazanması, mükemmeliyetçiliklerini yenebilme noktasında gerekli bilgi ve becerilerin geliştirilmesi ve onlara sunulması, kişisel doyum yaşayan daha mutlu bireyler yetişmesi açısından büyük bir öneme sahiptir. Aile tutumları mükemmelliyetçi bireylerin yetişmesinde önemli fonksiyonlara sahiptir (Kesici, Yalçın ve Kavaklı, 2016). Araştırmadan elde edilecek bulguların mükemmeliyetçi bireylere sunulan psikolojik danışma ve rehberlik hizmetlerinde alan çalışanlarına yol göstereceği beklenmektedir. Sonuç olarak bu araştırmanın, insan yaşamında önemli bir yeri olan mükemmeliyetçi tutumlara farklı bir bakış açısı getireceği, mükemmeliyetçilikle ilgili konularda hazırlanacak bilgilendirme programlarına, alandaki birikime ve sonraki çalışmalara ışık tutacağı düşünülmektedir. Buradan hareketle araştırmada

üniversite öğrencilerinin, bilişsel hatalarının ve duyguları ifade etmelerinin, mükemmeliyetçiliklerine iliş̧in varyansın ne kadarını açıkladığını ve bilişsel hatalar ile duyguları ifade etmenin mükemmeliyetçilikle arasında anlamlı bir ilişki olup olmadığı sorularına cevap aranmıştır.

\section{YÖNTEM}

\subsection{Araştırma Modeli}

Araştırmada ilişkisel tarama modeli kullanılmıştır. Bu modeli, bağımlı ve bağımsız değişkenler arasında anlamlı bir ilişki olup olmadığını belirlemek için kullanılmaktadır. Çalışmanın bağımlı değişkeni mükemmeliyetçilik iken bağımsız değişkenleri duyguları ifade etme ve bilişsel hatalardır.

\section{2 Çalışma Grubu}

Araştırmanın çalışma grubu, 2014-2015 eğitim öğretim yılında Necmettin Erbakan Üniversitesi Ahmet Keleşoğlu Eğitim Fakültesi'nin farklı bölümlerde, farklı sınıflarda öğrenim gören ve araştırmaya katılma konusunda gönüllü olan 458 üniversite öğrencisinden oluşmaktadır. Katılımcılar kolay ulaşılabilir örnekleme yöntemiyle seçilmiştir. Katılımcıların 377'si kız, 81'i erkektir. 
Katılımcıların 111'i birinci sınıf, 101'i ikinci sınıf, 201'i üçüncü sınıf ve 45'i dördüncü sınıf öğrencisidir. Katılımcıların 129'u Okul Öncesi Öğretmenliği, 147'si Rehberlik ve Psikolojik Danışmanlık, 27'si Din Kültürü Ve Ahlak Bilgisi Öğretmenliği, 64'ü Sınıf Öğretmenliği, 36'sı Illköğretim Matematik Öğretmenliği, 13'ü Türkçe Öğretmenliği, 28'i Edebiyat Öğretmenliği ve 14'ü Coğrafya Öğretmenliği bölümü öğrencisidir.

\subsection{Veri Toplama Araçları}

\subsubsection{Frost Çok Boyutlu Mükemmeliyetçilik Ölçeği}

Mükemmeliyetçiliğin birden fazla boyutta değerlendirebilmek amacıyla Frost ve diğerleri (1990)'nin geliştirdiği 35 maddeyi içeren bir ölçme aracıdır. Türkçeye Kağan (2011) tarafından adapte edilmiştir. Ölçek 6 alt ölçekten oluşmakta ve $5^{\prime}$ li likert tarzı ölçüm sağlamaktadır. Alt ölçekler, hatalara karşı duyarlıık, yüksek standartlar, aile beklentileri, ailesel eleştiri, davranışlarından şüphe duyma ve düzendir. FÇBMÖ'nün maddelerinin madde-toplam puan korelasyonları 0.21-0.63 arasındadır. Ölçme aracının özgün altı faktörlü yapısının Türk örneklemindeki yapı geçerliliği doğrulayıcı faktör analiziyle test edilmiştir. Satorra-Bentler normalite düzeltmeli yapısal eşitlik analizi sonucunda ölçeğin altı faktörlü orijinal yapısına ilişkin $\chi 2=1353.66$, sd=545; $p<0.01$, $\chi 2 / s d=2.48, \operatorname{RMSEA}=0.06(p<0.05) ; \mathrm{NFI}=0.94, \mathrm{CFI}=0.96$ ve SRMS=0.07 olarak hesaplanmıştır. Doğrulayıcı faktör analizi sonrasında hata yapma endişesi toplam varyansın \%22'sini, kişisel standartlar \%16'sını, ailesel beklentiler \%16'sını, ailesel eleştiri \%10'unu, davranışlardan şüphe duyma \%10'unu, düzen \%26'sını açıklamaktadır. FÇBMÖ'nün Cronbach alfa katsayısı 0.64 ve 0.94 arasındadır. Sınıf içi ilgileşim ise 0.63 ve 0.82 arasında değerler almıştır (Kağan, 2011). Mevcut çalışmada ölçeği Cronbach alfa katsayısı 0.90 olarak hesaplanmıştır.

\subsubsection{Duyguları İfade ölçeği}

Duyguları ifade ölçeği, King ve Emmons (1990) tarafından geliştirilmiş ve Türkçe'ye uyarlanması Kuzucu (2011) tarafından yapılmış olup 15 madde ve 3 alt boyuttan oluşur. Ölçek, 7'li likert tipi derecelendirme ölçeğidir. 6 . ve 14. ölçek maddeleri ters puanlanmaktadır. Ölçeğin alt boyutları olumlu duygu ifadesi, olumsuz duygu ifadesi ve yakınlık ifadesidir. Üç faktör, toplam varyansın \%35'ini açılmaktadır. Test-tekrar test $(n=96, r=.85)$ ve iç tutarlık analizleri $(\alpha=.85)$ ölçeğin güvenilir olduğunu göstermektedir. Ölçeğin en düşük maddeler arası korelasyonu .06, ortalama maddeler arası korelasyon .18, en yüksek maddeler arası korelasyonu ise .59 olarak hesaplanmıştır. Olumlu duygu ifadesi alt boyutunda 5 madde bulunmakta ve varyansın \%14'ünü açıklamaktadır. Yakınlık ifadesi alt boyutu 6 maddeden oluşmakta ve varyansın \%12'sini açıklamaktadır. Olumsuz duygu ifadesi alt boyutu 4 maddeden oluşmakta ve varyansın \%10'unu açıklamaktadır. Sonraki doğrulayıcı faktör analizleri açıklayıcı analizlerin oluştuğu grupların kullanımıyla yapılmıştır. Her grup, her biri az sayıda maddelerine nazaran yüksek güvenirlik katsayısına sahiptir; olumlu duygu ifade grubu için alfa .70; olumsuz duygu ifade grubu için alfa .64; yakınlık ifadesi grubu için alfa .68'tür (Kuzucu, 2011). Mevcut çalışmada ölçeği Cronbach alfa katsayısı 0.65 olarak hesaplanmıştır.

\subsubsection{Bilişsel Hatalar ölçeği}

Bu ölçek Lefebvre (1980) tarafından geliştirilmiştir. Türkçe'ye uyarlaması Alçalar ve Bahadır (2007) tarafından yapılmış ve 4'lü likert olmak üzere 0 (Hemen hemen benim düşüneceğimin aynısı)'dan 4 (Benim düşüneceğime hiç benzemiyor)'e bir derecelendirme ölçeğidir. Dört alt boyuttan oluşmakta ve her bir bilişsel hata için 6 madde olmak üzere toplam 24 madde bulunmaktadır. Her bir maddede günlük hayatta olabilecek bazı yaşam olayları öykülendirilmiştir. Bu öykülerin içeriğini iş, aile/ev yaşamı ve eğlence etkinlikleri oluşturmaktadır. Her birinin orijinal ölçekteki dağılımı eşittir. Tanımlanan her öyküyü, bir bilişsel hatayı yansıtan çarpıtılmış biliş takip etmektedir. Her bilişsel hata bir bilişsel çarpıtmanın sonucudur ya da kısa öyküde verilen bilgiye dayanarak yapılmış mantıksız çıkarımdır. Deneklere kısa öyküdeki benzer bir durumla karşılaştıklarında, ölçekte belirtilmiş olan bilişe ne kadar benzer bir düşüncenin akıllarından geçeceği sorulur. Ölçekten alınan düşük puan bilişsel hataların çokluğunu, ölçekten alınan yüksek puanlar bilişsel hataların azlığını göstermektedir. BHÖ' nün Cronbach alpha güvenirlik katsayısı .86 olarak bulunmuştur. 15 gün ara 
ile uygulanan test-tekrar test sonuçları arasındaki korelasyon $r=.86(p<.01)$, ölçeğin alt ölçekleri arasındaki korelasyon ise $r=.78(p<.01)$ olarak saptanmıştır. KMO oranının 0.88 ve Bartlett katsayısının anlamlı olduğu görülmüştür. Orijinal ölçekteki bilişsel hata kategorilerine (Kişiselleştirme, Felaketleştirme, Seçici Soyutlama ve Aşırı Genelleme) dayanılarak ve veriler dört faktörle sınırlandırılarak temel bileşenler analizi yapılmış ve varimaks yöntemi kullanılarak döndürülmüş bileşen matrisi hesaplanmıştır. Dört faktör toplam varyansın \% 41,94'ünü açıklamaktadır. Ölçeğin dört faktör üzerindeki dağııımına bakıldığında, soruların çoğunun 1 ve 2 . faktörlere yüklendiği saptanmıştır (Alçalar ve Bahadır, 2007). Mevcut çalışmada ölçeği Cronbach alfa katsayısı 0.89 olarak hesaplanmıştır.

\subsection{Verilerin Analizi}

Öncelikle, bilişsel hatalar ölçeğinden alınan düşük puanlar yüksek bilişsel hata düzeyini gösterdiği için diğer ölçeklerle uyumu için ölçek maddeleri ters puanlanmıştır. Araştırmada, veri toplama araçlarından elde edilen veriler değişkenlere göre kodlanarak SPSS 17.00 paket programında analiz edilmiştir. Analize geçmeden ölçeklerin alt boyutlarına ilişkin normallik testi yapılmıştır. Tabachnick ve Fidell (2013), çarpıklık ve basıklık değerlerinin -1.5 ile 1.5 arasında olması dağıımın normal olduğunu gösterir. Tablo 1 incelendiğinde ölçeklerin alt boyutlarına ilişkin verilerin normal dağıldığı görülmektedir.

Tablo 1: Kullanılan Ölçeklerin Alt Boyutlarına Ilişkin Normallik Testi Sonuçları

\begin{tabular}{lcc}
\hline Alt Boyutlar & Çarpıklık & Basıklık \\
\hline Olumlu Duygu ifadesi & -.22 & .17 \\
Olumsuz Duygu Ifadesi & -.78 & 1.12 \\
Yakınlık Ifadesi & -.23 & .34 \\
Hata Yapma Endişesi & .35 & -.19 \\
Kişisel Standartlar & .01 & -.31 \\
Aile Beklentileri & .21 & -.54 \\
Ailesel Eleştiri & .45 & -.03 \\
Yaptığından Emin & .21 & -.17 \\
Olamama & -1.08 & 1.3 \\
Düzen & .71 & -.01 \\
Felaketleştirme & .81 & .37 \\
Genelleme & .56 & -.49 \\
Kişiselleştirme & 1.4 & 1.5 \\
Seçici Soyutlama &
\end{tabular}

Üniversite öğrencilerinin, bilişsel hataları ve duyguları ifade etmelerinin mükemmeliyetçiliklerine ilişkin varyansın ne kadarını açıkladığını belirlemek için çoklu regresyon stepwise analizi kullanılmıştır. Değişkenler arasındaki ilişkiyi belirlemek için Pearson Korelasyon Katsayısı tekniği kullanılmıştır. 


\section{BULGULAR}

Bulgular araştırmanın alt amaçlarına göre verilmiştir.

Tablo 2. Duyguları ifade Etme ve Bilişsel Hatalar ile Mükemmeliyetçilik Arasındaki Illişki

\begin{tabular}{|c|c|c|c|c|c|c|}
\hline & 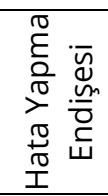 & 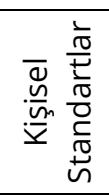 & 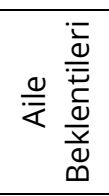 & 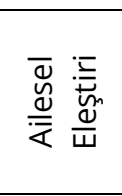 & 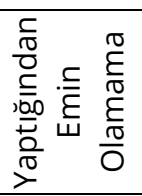 & : \\
\hline $\begin{array}{l}\text { Olumlu Duygu } \\
\text { Ifadesi }\end{array}$ & .047 & .003 & $.094^{*}$ & .005 & $.103^{*}$ & $-.155^{\star *}$ \\
\hline $\begin{array}{l}\text { Olumsuz Duygu } \\
\text { Ifadesi }\end{array}$ & .078 & .074 & .074 & .048 & .040 & .037 \\
\hline Yakınlık ifadesi & -.084 & .043 & .019 & $-.124^{* *}$ & -.050 & .032 \\
\hline Felaketleştirme & $.352^{* *}$ & $.123^{\star *}$ & $.110^{*}$ & $.273^{\star *}$ & $.277^{\star \star}$ & .040 \\
\hline Genelleme & $.326^{* *}$ & .083 & $.117^{*}$ & $.298^{* *}$ & $.265^{* *}$ & -.023 \\
\hline Kişiselleştirme & $.348^{* *}$ & $.127^{\star \star}$ & $.107^{*}$ & $.270^{\star \star}$ & $.252^{\star \star}$ & .024 \\
\hline Seçici Soyutlama & $.250^{\star *}$ & .014 & .032 & $.205^{\star *}$ & $.204^{\star *}$ & -.036 \\
\hline
\end{tabular}

Tablo 2'ye göre; duyguları ifade ölçeğinin, olumlu duygu ifadesi alt boyutu ile aile beklentileri $(r=.094, p<.05)$ ve yaptığından emin olamama arasında $(r=.103, p<.05)$ pozitif yönlü anlamlı bir ilişki bulunurken düzen ile arasında negatif yönlü $(r=-.155, p<.01)$ anlamlı bir ilişki bulunmuştur. Duyguları ifade ölçeğinin, yakınlık ifadesi alt boyutu ile ailesel eleştiri arasında negatif yönlü ( $r=-$ $.124, p<.01)$ anlamlı bir ilişki bulunmuştur. Bilişsel hatalar ölçeğinin felaketleştirme alt boyut ile hata yapma endişesi $(r=.352, p<.01)$, kişisel standartlar $(r=.123, p<.01)$, aile beklentileri $(r=.110$, $p<.01)$, ailesel eleştiri $(r=.273, p<.01)$ ve yaptığından emin olamama $(r=.277, p<.01)$ arasında pozitif yönlü anlamlı bir ilişki bulunmuştur. Bilişsel hatalar ölçeğinin genelleme alt boyut ile hata yapma endişesi $(r=.326, p<.01)$, aile beklentileri $(r=.117, p<.01)$, ailesel eleştiri $(r=.298, p<.01)$ ve yaptığından emin olamama $(r=.265, p<.01)$ arasında pozitif yönlü anlamlı bir ilişki bulunmuştur. Bilişsel hatalar ölçeğinin kişiselleştirme alt boyut ile hata yapma endişesi $(r=.348, p<.01)$, kişisel standartlar ( $r=.127$, $p<.01)$, aile beklentileri $(r=.107, p<.01)$, ailesel eleştiri $(r=.270, p<.01)$ ve yaptığından emin olamama $(r=.252, p<.01)$ arasında pozitif yönlü anlamlı bir ilişki bulunmuştur. Bilişsel hatalar ölçeğinin seçici soyutlama alt boyut ile hata yapma endişesi $(r=.250, p<.01)$, ailesel eleştiri $(r=.205, p<.01)$ ve yaptığından emin olamama $(r=.204, p<.01)$ arasında pozitif yönlü anlamlı bir ilişki bulunmuştur.

Tablo 3. Üniversite Öğrencilerinin Duyguları İfade Etmesinin Düzen Değişkenini Yordamasına Ait Regresyon Analizi Sonuçları

\begin{tabular}{lcccccc}
\hline Model & $\mathrm{R}$ & $\mathrm{R}^{2}$ & $\mathrm{R}^{2}(\mathrm{Adj})$ & Standart Hata & $\mathrm{F}$ & $\mathrm{p}$ \\
\hline Olumlu Duygu ifadesi & .155 & .024 & .022 & 5.10998 & $11.226^{*}$ & .001 \\
\hline
\end{tabular}

Tablo 4. Üniversite Öğrencilerinin Duyguları Ifade Etmesinin Ailesel Beklentiler Değişkenini Yordamasına Ait Regresyon Analizi Sonuçları

\begin{tabular}{lcccccc}
\hline Model & $\mathrm{R}$ & $\mathrm{R}^{2}$ & $\mathrm{R}^{2}($ Adj) & Standart Hata & $\mathrm{F}$ & $\mathrm{P}$ \\
\hline Olumlu Duygu ifadesi & .094 & .009 & .007 & 4.43902 & $4.082^{*}$ & .044 \\
\hline
\end{tabular}


Tablo 5. Üniversite Öğrencilerinin Duyguları Ifade Etmesinin Ailesel Eleştiri Değişkenini Yordamasına Ait Regresyon Analizi Sonuçları

\begin{tabular}{lcccccc}
\hline Model & $\mathrm{R}$ & $\mathrm{R}^{2}$ & $\mathrm{R}^{2}$ (Adj) & Standart Hata & $\mathrm{F}$ & $\mathrm{p}$ \\
\hline Yakınlık Ifadesi & .124 & .015 & .013 & 3.54628 & $7.070^{*}$ & .008
\end{tabular}

Tablo 6. Üniversite Öğrencilerinin Duyguları İfade Etmesinin Yaptığından Emin Olamama Değişkenini Yordamasına Ait Regresyon Analizi Sonuçları

\begin{tabular}{lcccccc}
\hline Model & $\mathrm{R}$ & $\mathrm{R}^{2}$ & $\mathrm{R}^{2}($ Adj) & Standart Hata & $\mathrm{F}$ & $\mathrm{p}$ \\
\hline Olumlu Duygu ifadesi & .103 & .011 & .009 & 3.41242 & $4.918^{*}$ & .027 \\
\hline
\end{tabular}
${ }^{*} \mathrm{p}<0.05$

Tablo 2'ye göre; olumlu duygu ifadesi, düzen değişkeninin önemli bir yordayıcısı olduğu görülmektedir $(p<0.05)$. Olumlu duygu ifadesi düzene ilişkin varyansın \%2.4'ünü açıklamaktadır. Tablo 3'de görüldüğü gibi; olumlu duygu ifadesi, ailesel beklentiler değişkeninin önemli bir yordayıcısı olarak bulunmuştur $(p<0.05)$. Olumlu duygu ifadesi ailesel beklentilere ilişkin ilişkin varyansın \%0.9'unu açıklamaktadır. Tablo 4'e göre; yakınlık, ailesel eleştiri değişkeninin önemli bir yordayıcısı olarak bulunmuştur $(p<0.05)$. Olumlu duygu ifadesi düzene ilişkin varyansın $\% 1.5^{\prime}$ ini açıklamaktadır. Tablo 5'e göre; olumlu duygu ifadesi, yaptığından emin olamama değişkeninin önemli bir yordayıcısı olarak bulunmuştur $(p<0.05)$. Olumlu duygu ifadesi yaptığından emin olamamaya ilişkin varyansın \%1.1'ini açıklamaktadır.

Table 7. Üniversite Öğrencilerinin Bilişsel Hatalarının Hata Yapma Endişesi Değişkenini Yordamasına Ait Regresyon Analizi Sonuçları

\begin{tabular}{lllllll}
\hline Model & $\mathrm{R}$ & $\mathrm{R}^{2}$ & $\mathrm{R}^{2}$ (Adj) & Standart Hata & $\mathrm{F}$ & $\mathrm{P}$ \\
\hline Felaketleştirme & .352 & .124 & .122 & 5.64878 & $64.655^{*}$ & .000 \\
Felaketleştirme ve Kişiselleştirme & .392 & .153 & .150 & 5.56009 & $41.198^{*}$ & .000 \\
\hline
\end{tabular}

Table 8. Üniversite Öğrencilerinin Bilişsel Hatalarının Kişisel Standartlar Değişkenini Yordamasına Ait Regresyon Analizi Sonuçları

\begin{tabular}{lcccccc}
\hline Model & $\mathrm{R}$ & $\mathrm{R}^{2}$ & $\mathrm{R}^{2}(\mathrm{Adj})$ & Standart Hata & $\mathrm{F}$ & $\mathrm{p}$ \\
\hline Kişiselleştirme & .127 & .016 & .014 & 5.275127 & $7.457^{\star}$ & .007 \\
\hline
\end{tabular}

Table 9. Üniversite Öğrencilerinin Bilişsel Hatalarının Ailesel Beklentiler Değişkenini Yordamasına Ait Regresyon Analizi Sonuçları

\begin{tabular}{lcccccc}
\hline Model & $\mathrm{R}$ & $\mathrm{R}^{2}$ & $\mathrm{R}^{2}($ Adj) & Standart Hata & $\mathrm{F}$ & $\mathrm{p}$ \\
\hline Genelleme & .117 & .014 & .012 & 4.42824 & $6.325^{*}$ & .012 \\
\hline
\end{tabular}

Table 10. Üniversite Öğrencilerinin Bilişsel Hatalarının Ailesel Eleştiri Değişkenini Yordamasına Ait Regresyon Analizi Sonuçları

\begin{tabular}{lcccccc}
\hline Model & $\mathrm{R}$ & $\mathrm{R}^{2}$ & $\mathrm{R}^{2}$ (Adj) & Standart Hata & $\mathrm{F}$ & $\mathrm{p}$ \\
\hline Genelleme & .298 & .089 & .087 & 3.41096 & $44.538^{*}$ & .000 \\
Genelleme ve Kişiselleştirme & .311 & .097 & .093 & 3.39971 & $24.429^{*}$ & .000 \\
\hline
\end{tabular}


Table 11. Üniversite Öğrencilerinin Bilişsel Hatalarının Yaptığından Emin Olamama Değişkenini Yordamasına Ait Regresyon Analizi Sonuçları

\begin{tabular}{lcccccc}
\hline Model & $\mathrm{R}$ & $\mathrm{R}^{2}$ & $\mathrm{R}^{2}$ (Adj) & Standart Hata & $\mathrm{F}$ & $\mathrm{p}$ \\
\hline Felaketleştirme & .277 & .077 & .075 & 3.29629 & $37.966^{*}$ & .000 \\
Felaketleştirme ve Kişiselleştirme & .297 & .088 & .084 & 3.27937 & $22.038^{*}$ & .000 \\
\hline
\end{tabular}

${ }^{*} \mathrm{p}<0.05$

Tablo 6'da görüldüğü gibi; felaketleştirme; hata yapma endişesinin önemli bir yordayıcısı olarak bulunmuştur $(p<0.05)$. Felaketleştirme, hata yapma endişesine ilişkin varyansın \%12.4'ünü açıklamaktadır. Felaketleştirme, kişiselleştirme ile birlikte hata yapma endişesi değişkeninin önemli bir yordayıcısı olarak bulunmuştur $(p<0.05)$. Felaketleştirme ve kişiselleştirme birlikte hata yapma endişesine ilişkin varyansın \%15.3'ünü açıklamaktadır. Tablo 7'de görüldüğü gibi; kişiselleştirme, kişisel standartlar değişkeninin önemli bir yordayıcısı olarak bulunmuştur $(p<0.05)$. Kişiselleştirme, kişisel standartlara ilişkin varyansın \%1.6'sını açıklamaktadır. Tablo 8'de görüldüğü gibi; genelleme, ailesel beklentiler değişkeninin önemli bir yordayıcısı olarak bulunmuştur $(p<0.05)$. Genelleme, ailesel beklentilere ilişkin varyansın \%1.4'ünü açıklamaktadır. Tablo 9'da görüldüğü gibi; genelleme, ailesel eleştiri değişkeninin önemli bir yordayıcısı olarak bulunmuştur $(p<0.05)$. Genelleme, ailesel eleştiriye ilişkin varyansın \%8.9'unu açıklamaktadır. Genelleme, kişiselleştirme ile birlikte ailesel eleştiri değişkeninin önemli bir yordayıcısı olarak bulunmuştur $(p<0.05)$. Genelleme ve kişiselleştirme birlikte ailesel eleştiriye ilişkin varyansın \%9.7'sini açıklamaktadır. Tablo 10'da görüldüğü gibi; felaketleştirme, yaptığından emin olamamanın önemli bir yordayıcısı olarak bulunmuştur $(p<0.05)$. Felaketleştirme, yaptığından emin olamamaya ilişkin varyansın \%7.7'sini açıklamaktadır. Felaketleştirme, kişiselleştirme ile birlikte yaptığından emin olamama değişkeninin önemli bir yordayıcısı olarak bulunmuştur $(p<0.05)$. Felaketleştirme ve kişiselleştirme birlikte yaptı̆̆ından emin olamamaya ilişkin varyansın \%8.8'ini açıklamaktadır.

\section{SONUÇ, TARTIŞMA VE ÖNERILER}

Araştırma bulgularına göre olumlu duygu ifadesi ile düzen arasında, yakınlık ifadesi ile ailesel eleştiri arasında düşük düzeyde negatif yönlü anlamlı bir ilişki bulunmuştur. Ayrıca olumlu duygu ifadesi, düzen boyutunun; yakınlık ifadesi ise ailesel eleştiri boyutunun önemli bir yordayıcısı olarak bulunmuştur. Bu sonuçlara göre üniversite öğrencilerinin, olumlu duygu ifadesi kullanımları arttıkça temizlik, düzen ve intizam ile ilgili aşırı bir dürtü duyma seviyelerinin düşeceği söylenebilir. Ayrıca duygularını yakınlık davranışları ile ifade eden üniversite öğrencilerinin ailesel eleştiri düzeylerinin düşük olduğu söylenebilir.

Literatür incelendiğinde mükemmeliyetçiliğin duygusal zekâ (Smith, Saklofske ve Nordstokle, 2014; Kaya, 2015), duyguları düzenleme stratejileri (Bergman, Nyland ve Burns, 2007; Aldea ve Rice, 2006) ile negatif yönde; duyguları bastırma (Nyland, 2004; Garrison, 2014), kendini gizleme (Kawamura ve Frost, 2004) ile pozitif yönde ilişkili olduğu görülmektedir. Literatürde mükemmeliyetçilikle ilişkili değişkenlere bakıldığında üniversite öğrencilerinin, olumlu duygu ifadesi kullanımları arttıkça temizlik, düzen ve intizam ile ilgili aşırı bir dürtü duyma seviyelerinin düşük olduğu, duygularını yakınlık davranışları ile ifade eden üniversite öğrencilerinin ailesel eleştiri düzeylerinin düşük olduğu sonucunu destekler nitelikte olduğu söylenebilir. Araştırma sonuçları dikkatle incelenirse, mükemmeliyetçi kişilerin; öz bilinç ve öz denetimi düşük, empatik eğilimleri zayıf ve duygularını ifade edebilme konusunda yetersiz olduğu söylenebilir. Ayrıca mükemmeliyetçi bireylerin duyguları düzenleme becerilerinin düşük olduğu, dolayısıyla duyguları bastırma, ifade etmeme yoluna gittiğ düşünülebilir. Greenberg (2012), duyguları düzenleme duygusal zekânın bir parçasıdır ve bireyler hem duyguları ile hareket edebilmeyi, sakinleştirmeyi hem de ifade edebilmeyi isterler. Duyguları bastırma ve yüksek standartların aynı şema alanı içerisinde olduğu ve köken olarak talepkar, eleştirel, cezalandırıcı ve baskılayıcı aile yapısının etkin olduğu (Arntz ve Genderen, 2013; Young, Kolosko, ve Weishaar, 2009; Young ve Klosko, 2013; Jacob, Genderen ve Seebauer, 2014), aile 
bireyleri arasındaki yakın bağların çocuğun kendisini ifade etmesini etkilediği ve bu yakın bağlar ailede dayanışma sağlarken, baskıcı durumun çocuğun özerklik yönelimlerini engellediği (Kağıtçıbaşı, 1993), aile içerisinde kendini ifade edebilen üniversite öğrencilerinin kendini daha az ifade edebilen veya hiç edemeyen öğrencilere göre duygularını daha çok yakınlık ifadesi olarak sergiledikleri (Yalçın, 2010) dikkate alındığında olumlu duygu ifadesi ile düzen arasındaki; yakınlık ifadesi ile ailesel eleştiri arasındaki negatif yönlü ilişki daha anlaşılabilir hale gelebilir.

Araştırmanın diğer bir bulgusuna göre olumlu duygu ifadesi ile aile beklentileri ve yaptığından emin olamama arasında düşük düzeyde pozitif yönlü anlamlı bir ilişki bulunmuştur. Ayrıca olumlu duygu ifadesi, aile beklentileri ve yaptığından emin olamama boyutlarının önemli bir yordayıcısı olarak bulunmuştur. Bu sonuçlar doğrultusunda üniversite öğrencilerinin olumlu duygu ifadeleri artıkta algıladıkları ailesel beklentilerin ve yaptığından emin olamamanın da artacağı düşünülebilir.

Mükemmeliyetçi bireylerin, duygularını açığa vurmayı reddettikleri (Ben-Sharar, 2014) ve kendini aşırı eleştirel değerlendiren insanların, kişisel sorunlarını gizleme eğilimi içerisinde oldukları (Kawamura ve Frost, 2004; Frost, vd., 1997; Frost, vd., 1995) düşünüldüğünde, olumlu duygu ifadesi ile aile beklentileri ve davranışlardan şüphe arasındaki ilişki, benzer çalışmalarla tutarlıık göstermemektedir.

Parrot (2001), insanlar övüldüklerinde mutlu hissetmekte, eleştirildiklerinde üzüntü duymaktadırlar. Duyguların açığa çıkarılmasında, o anki yaşanan duygu değil, sosyal ortamın gerektirdiği duygu açığa çıkar. Bireyler, sosyal taleplere göre duygularını ifade etme ve olumsuz hislerini sık sık saklama, olumlu duygularını ise sosyal talebe göre abartma eğilimindedirler. Yani bireyin ailesinden gelen sosyal işaretler önemlidir. Mükemmeliyetçi bireylerin, ebeveynlerinin takdir ve onayını almak, ceza ve eleştirilerinden kaçınmak için ailesi tarafından belirlenen yüksek standartlar ve bu standartlara ulaşamama sonucu yaşadığı olumsuz duygularını gizledikleri ve sosyal talep doğrultusunda yaşanmayan olumlu duyguları sergileme eğilimi gösterdikleri düşünülebilir. Ayrıca, mükemmeliyetçi bireylerin, olumlu duygu ifadesi kullanmaları, kendini kusursuz olarak yansıtma nevrotik ihtiyacına (Flett ve Hewitt, 2002) hizmet ediyor olabilir.

Araştırmanın diğer bulgularına göre felaketleştirme; hata yapma endişesi, kişisel standartlar, aile beklentileri, ailesel eleştiri ve davranışlardan şüphe ile, kişiselleştirme; hata yapma endişesi, kişisel standartlar, aile beklentileri, ailesel eleştiri ve davranışlardan şüphe ile, genelleme; hata yapma endişesi, aile beklentileri, ailesel eleştiri ve davranışlardan şüphe ile, seçici soyutlama; hata yapma endişesi ailesel eleştiri ve davranışlardan şüphe ile düşük düzeyde pozitif yönlü anlamlı bir ilişki içinde bulunmuştur. Ayrıca felaketleştirme; hata yapma endişesinin, felaketleştirme, kişiselleştirme ile birlikte hata yapma endişesinin; felaketleştirme, yaptığından emin olamamanın, felaketleştirme, kişiselleştirme ile birlikte yaptığından emin olamamanın; kişiselleştirme, kişisel standartların; genelleme, ailesel beklentilerin; genelleme, ailesel eleştiri değişkeninin; genelleme, kişiselleştirme ile birlikte ailesel eleştiri değişkeninin önemli bir yordayıcısı olarak bulunmuştur. Bu sonuçlar bilişsel hataların mükemmeliyetçilik için önemli bir değişken olduğunu gösterebilir. Bulgulardan anlaşılmaktadır ki bilişsel hatalar (felaketleştirme, genelleme, kişiselleştirme, seçici soyutlama) arttıkça mükemmeliyetçilik de artabilir.

Konu ile ilgili yapılan benzer çalışmalar incelendiğinde mükemmeliyetçiliğin bilişsel hatalar (Davis ve Wosinski, 2012), ikili düşünme (Egan, vd., 2007; Burns ve Fedawa, 2005) ve mantık dışı inançlar (Flett, vd., 1991; Flett, vd., 2008) ile pozitif yönde ilişkiliyken yapıcı düşünmeyle negatif yönde (Flett, Hewitt ve Russo, 1994) ilişkili olduğu görülmektedir. Ayrıca olumsuz mükemmeliyetçilik, olumsuz otomatik düşünceler (Bergman, vd., 2007; Nyland, 2004) ve fonksiyonel olmayan tutumlar (Nyland, 2004) ile pozitif yönde ilişkilidir ve yüksek standartlar şeması, olumsuz otomatik düşünceler (Kevlekçi, 2013; Rafaeli, Bernstein ve Young, (2013) ile pozitif yönde korelasyon göstermektedir. Konu ile ilgili yapılan önceki çalışmalarda elde edilen bulgular, araştırma bulgularını desteklemektedir. Bu çalışma sonuçları incelendiğinde mükemmeliyetçi bireylerin olumsuz bilişsel yapılara sahip oldukları görülmektedir. Flett, Hewitt, Blankstein ve Gray (1998), mükemmeliyetçi bilişlerin kendine yönelik tutumlarla ilişkisini incelediği çalışma sonucunda mükemmeliyetçi 
bilişlerin, kendine yüksek standartlar belirleme, genelleme yapma, öz eleştiri yapma ve başarısızlığın yineleneceğini düşünme ile aynı yönde bir ilişkisi olduğunu tespit etmişlerdir. Ellis (2002), gerekirci düşüncelerin özellikle; mümkün olan her alanda başarılı ve yeterli olma zorunluluğu, bir şeyler yolunda gitmediğinde korkunç bir şey olduğu düşüncesi, sorunların doğru, mutlak ve harika tek bir çözümü olduğu ve bu mükemmel çözüm bulunamaması sonucu kendini acımasızca etiketleme mükemmeliyetçilikle alakalıdır. Mükemmeliyetçi bireylerin, katı standartlara ulaşamadığında tamamen başarısız olduğunu düşünen, tek bir duruma göre kendisine başarısız etiketi yapıştıran, performansın olumsuz yönlerine odaklanarak olumlu yönlerini hafife alan, olayın tüm sorumluluğunu üstlenerek durumun yaratabileceği olası sonuçları felaket olarak yorumlama eğiliminde oldukları (Shafran, Egan ve Wade, 2010; Antony ve Swinson, 2000; Ben-Shahar, 2014; Barrow ve Moore, 1983) ve katı ve yüksek standartlar koyma, bu performansa ulaşmak için gösterdiği performansını yetersiz bulma ve yetenekleri konusunda endişe duyma gibi gerçekçi olmayan düşüncelere sahip oldukları (Enns, Cox ve Clara, 2002) düşünüldüğünde bilişsel hatalar ve mükemmeliyetçilik arasındaki ilişki açık bir şekilde görülmektedir. Özetle üniversite öğrencilerinin kendilerini baskı altında hissetmeyerek, yüksek standartlarını düşürerek öğrenciler daha mutlu olabilir (Yalçın, Ak, Kavaklı ve Kesici, 2018). Öğrencilerin mutlu olabilmesi için süreç olarak ilköğretimden yüksek öğretime kadar öğretmen davranışlarının olumlu ve olumsuz sonuçlarına dikkat ederek hedeflerini yeniden yapılandırmalıdırlar (Büyükkaragöz ve Kesici, 1998). Bunu yaparken de özellikle düşünce hatalarının olumsuz etkilerini azaltmak ve duygularını ifade etmek için problem çözme, çatışma çözme gibi becerileri kazanmaları gerekmektedir (Izgar, Gürsel, Kesici ve Negiş, 2004).

\section{1 Öneriler}

Araştırma bulgularının genellenebilmesi için farklı şehirlerde farklı örneklem guruplarına yeni araştırmalar yapılmasının önemli olduğu düşünülmektedir. Aile ve öğretmenlerden başlayarak toplumun farklı kesimlerine, bilişsel yapılar ve duyguları ifade konularında bilinçlendirme çalışmaları yapılabilir. Duyguları yazarak ifade etmenin, duyguları anlamlandırma ve kabullenme noktasında önemli bir yeri olduğu düşünüldüğünde, mükemmeliyetçi bireylerin duygularını ifade etmeleri üzerine yapılacak çalışmaların, duygularını yazarak ifade etmeye dayanan nitel çalışmalardan oluşmasının daha ayrıntılı bilgiler sunacağı düşünülmektedir. Bireysel ve grupla psikolojik danışma hizmetleri veren alan çalışanları mükemmeliyetçilik problemi yaşayan ve bilişsel hatalara sahip danışanlarla karşılaşabilmektedir. Uzmanların, danışma sürecinde mükemmeliyetçilik sorunlarına eğilirken bilişsel hatalara vurgu yapması mükemmeliyetçilik sorunlarının azalmasını sağlayabilir.

\section{Kaynakça}

Adler, A. (2000). Yaşamın Anlam ve Amacı. (Çev. Kamuran Şipal). İstanbul: Say Yayınları.

Alçalar, N. ve Bahadır, G. (2007). Bilişsel Hatalar Ölçeği (BHÖ) Gerçeklik ve Güvenirlik Çalışması. Türk Psikoloji Yazıları, 10(19), 77-89.

Aldea, M. A. ve Rice, K. G. (2006), The Role of Emotional Dysregulation in Perfectionism and Psychological Distress. Journal of Conseling Psychology, 53(4), 498-510.

Antony, M. M. ve Swinson, R. P. (2000). Mükemmeliyetçilik, Dost Sandığınız Düşman (Çeviren: Aslı Açıkgöz). İstanbul: Kuraldışı Yayınevi.

Arntz, A. ve Genderen, H. V. (2014). Sınırda Kişilik Bozukluğu, (2.b.). (Çev. M., Şaşığulu, N., Azizlerli). İstanbul: Psikonet Yayınları.

Barrow, J. C. ve Moore, C. A. (1983). Group Interventions with Perfectionistic Thinking. The Personnel and Guidance Journal, 61(10), 612-615.

Batmaz, S., Koçbıyık, S. ve Yunca, Ö. A. (2015). Turkish Version of The Cognitive Distortions Questionnaire: Psychometric Properties. Depression Research and Treatment, 1-8. 
Beck, J. S. (2014). Bilişsel Davranış̧̧ı Terapi Temelleri ve Ötesi, (2.b.). (Çev. M. Şahin ve I. T. Cömert) Ankara: Nobel Yayıncilık.

Ben-Shahar, T. (2014). Mükemmeli Aramak: Mutluluğun Önündeki Duvar, (2.b.). (Çev. B. Akat). Ankara: Elma-Akademi Artı Yayınevi.

Bergman, A. J., Nyland, J. E. ve Burns, L. R. (2007). Correlates with Perfectionism and the Utility of a Dual Process Model. Personality and Individual Differences, 43(2), 389-399.

Blake, E., Dobson, K. S., Sheptycki, A. R. ve Drapeau, M. (2016). Changes in Cognitive Errors Over the Course of Cognitive Therapy for Depression. Journal of Cognitive Psychotherapy, 30(1), 16-34.

Burns, D. (2012). lyi Hissetmek, (13.b.). (Çev. E. Tuncer, Ö. Mestçioğlu, I. E. Atak ve G. Acar) İstanbul: Psikonet.

Burns, L. R. ve Fedawa, B. A. (2005). Cognitive Styles: Links with Perfectionistic Thinking. Personality and Individual Differences, 38(1), 1003-113.

Büyükkaragöz, S. S. ve Kesici, Ş. (1998). Eğitimde öğretmenin rolü ve öğretmen tutumlarının öğrenci davranışları üzerindeki etkisi. Milli Ĕgitim Dergisi, 137, 68-73.

Charry, W., Campelli, H., Bydlowski, S., Chevallier, J. ve Consoli, S. M. (2004). Emotional Awareness and Social Anxiety in Obese Patients Waiting for Gastric Banding Surgery. Journal of Psychosomatic Research, 56(6), 602.

Davis, M. C. ve Wosinski, N. L. (2012). Cognitive Errors as Predictors of Adaptive and Maladtive Perfectionism in Children. Journal of Rational-Emotive and Conitive-Behavior Therapy, 30(2), 105117.

Dökmen, Ü. (2010). Iletişim Çatışmaları ve Empati, (42.b.). İstanbul: Remzi Kitabevi.

Dönmez, M. M. (2007). Meslek Lisesi Öğrencilerinin Atılganlık Düzeylerine Göre Yaşam Doyumu ve Duyguları Ifade Etme Eğilimlerinin Karşılaştııılması. Yayınlanmamış Yüksek Lisans Tezi. Ankara Üniversitesi, Eğitim Bilimleri Enstitüsü, Ankara.

Egan, S. J., Piek, J. P., Dyck, M. J. ve Rees, C. S. (2007). The Role of Dichotomous Thinking and Rigidity in Perfectionism. Behaviour Research and Therapy, 45(8), 1813-1822.

Ellis, A. (1987). A Sadly Neglected Cognitive Element in Depression. Cognitive Therapy and Research, 11(1), 121-145.

Ellis, A. (2002). The Role of Irrational Beliefs in Perfectionism, Perfectionism: Theory, Research, and Treatment. In G. Flett and P. L. Hewitt (Eds.), Washington DC: American Psychological Association.

Enns, M. W., Cox, B. J. ve Clara, I. (2002). Adaptive and Maladaptive Perfectionism: Developmental Origins and Association with Depression Proneness. Personality and Individual Differences, 33(6), 921-935.

Ergin, E. (2000). Üniversite Öğrencilerinin Sahip Oldukları Duygusal Zeka Düzeyleri Ile 16 Kişilik Özelliği Arasında İlişki Üzerine Bir Araştırma. Yayınlanmamış Yüksek Lisans Tezi. Selçuk Üniversitesi, Sosyal Bilimler Enstitüsü, Konya.

Flett, G. L., Hewitt, P. L. ve Cheng, W. M. W. (2008). Perfectionism, Distress, and Irrational Beliefs in High School Students: Analyses with an Abbreviated Survey of Personal Beliefs for Adolescents. Journal of Rational-Emotive and Cognitive-Behavior Therapy, 26(3), 194-205.

Flett, G. L., Hewitt, P. L. ve Rudolph, S. G. (2007). Perfectionism and Deficits in Cognitive Emotion Regulation. Journal of Rational-Emotive and Conitive-Behavior Therapy, 25(4), 343-357.

Flett, G. L., Hewitt, P. L., Blankstein, K. R. ve Gray, L. (1998). Psychological Distress and the Frequency of Perfectionistic Thinking. Journal of Personality and Social Psychology, 75(5), 13631381.

Flett, G., ve Hewitt, P. L. (2002). Perfectionism and Maladjustment: An Overview of Theoetical, Definition and Treatment Issue. Perfectionism: Theory, Research and Treatment (Ed: G. Flett and P. L. Hewitt). Washington DC: American Psychological Association. 
Flett. G.L., Russo F.A. ve Hewitt. P.L. (1994). Dimensions of Perfectionism and Constructive Thinking as a Coping Response. Journal Journal of Rational Emotive and Cognitive Behavior Therapy, 12, 163-179.

Frost, R. O., Hunt, S. L., Kawamura, K. Y. ve Dibartolo, P. M. (2001). Perfectionism, Anxiety, and Depression: Are the Relationships Independent? Cognitive Therapy and Research, 25(3), 291-301.

Frost, R. O., Marten, P., Lahart, C. ve Rosenblate, R. (1990). The Dimensions of Perfectionism. Cognitive Therapy and Research, 14(5), 449-468.

Frost, R. O., Trepanler, K. L., Brown, E. J., Heimberg, R. G., Juster, H. R., Makris, G. S. ve Leung, A. W. (1997). Self-Monitoring of Mistakes Among Subjects High and Low in Perfectionistic Concern Over Mistakes. Cognitive Therapy and Research, 21(2), 209-222.

Frost, R. O., Turcotte, T. A., Heimberg, R. G., Mattia, J. I., Holt, C. S. ve Hope, D. A. (1995). Reactions to Mistakes Among Subjects High and Low in Perfectionistic Concern Over Mistakes. Cognitive Therapy and Research, 19(2), 195-205.

Garrison, A. M. (2014). Testing a Model of Maladaptive Perfectionism and Depression Symptoms: The Roles of Emotional Disclosure, Emotion Regulation Strategies, Adult Attachment, and Shame. Yayınlanmamış Doktora Tezi. Western Michigan University, Michigan.

Gönen, G. (2014). Algılanan Anne Baba Tutumunun Üniversite Öğrencilerinin Bilişsel Çarpıtmaları ve Kişilik Yapıları Ile Ilişkisi. Yayınlanmamış Yüksek Lisans Tezi. Dokuz Eylül Üniversitesi, Eğitim Bilimleri Enstitüsü, İzmir.

Greenberg, L. S. (2012). Duygu Odaklı Terapi. (Serpil Kızıltaş, Çev.) İstanbul: Psikoterapi Enstitüsü Eğitim Yayınları.

Hamachek, D. E. (1978). Psychodynamics of Normal and Neurotic Perfectionism. Psychology, 15(1), 27-33.

Hewitt, P. L., ve Flett, G. L. (1991). Dimensions of Perfectionism in Unipolar Depression. Journal of Abnormal Psychology, 100(1), 98-101.

Horney, K. (1995). Çă̆ımızın Nevrotik Kişiliği. (Çeviren: Selçuk Budak). İstanbul: Öteki Yayınevi.

Izgar, H., Gürsel, M., Kesici, Ş. ve Negiş, A. (2004). Önder davranışlarının problem çözme becerisine etkisi. XIII. Ulusal Eğitim Bilimleri Kurultayı, 6-9.

Jacob, G., Genderen, H. V. ve Seebauer, L. (2014). Mod Terapisi: Diğer Yollardan Gitmek, (2.b.). (N. Azizlerli ve M. Soykut, Çev.) İstanbul: Psikonet Yayınları.

Kağan, M. (2011). Frost Çok Boyutlu Mükemmeliyetçilik Ölçeği'nin Türkçe Formunun Psikometrik Özellikleri. Anadolu Psikiyatri Dergisi, 12(3), 192-197.

Kağıtçıbaşı, Ç. (1993). Insan, Aile, Kültür. Remzi Kitabevi: İstanbul.

Kawamura, K. Y., ve Frost, R. (2004). Self-Concealment as A Mediator in The Relationship Between Perfectionism and Psychological Distress. Cognitive Therapy and Research, 28(2), 183-191.

Kaya, F. (2015). Üniversite Öğrencilerinin Affetme Ve Mükemmeliyetçilik Düzeyleri Arasındaki ilişki: Duygusal Zekanın Aracı Rolü. Yayınlanmamış Yüksek Lisans Tezi, Atatürk Üniversitesi Eğitim Bilimleri Enstitüsü, Erzurum.

Kesici, Ş., Yalçın, S. B. ve Kavaklı, M. (2016). Affedici Bir Gençlik için Anne ve Babalar Ne Yapmali? Ankara: Nobel Yayınevi

Kevlekçi, M. (2013). Erken Dönem Uyumsuz Şemalar, Tutmlar Ve Hatalı Otomatik Düşüncelerin Depresif Duygudurum ve Intihar Düşüncelerine Etkisi. Yayınlanmamış Yüksek Lisans Tezi. Haliç Üniversitesi, Sosyal Bilimler Enstitüsü, İstanbul.

King, L. A. ve Emmons, R. A. (1990). Conflict over Emotional Expression: Psychological and Psysical Correlates. Journal of Personality and Social Psychology, 58(5), 64-877.

Kınık, Ö. (2015). Üniversite Öğrencilerinin Akademik Erteleme Davranış/arı Ile Fonksiyonel Olmayan Tutumları, Depresyon Düzeyleri Ve Benlik Saygıları Arasındaki ilişki. Yayınlanmamış Yüksek Lisans Tezi. Karadeniz Teknik Üniversitesi, Eğitim Bilimleri Enstitüsü, Trabzon. 
Koçak, R. (2002). Aleksitimi: Kuramsal Çerçeve Tedavi Yaklaşımları ve ilgili Araştırmalar. Ankara Üniversitesi Eğitim Bilimleri Fakültesi Dergisi, 35(1-2), 184-212.

Köknel, Ö. (1997). Kaygıdan Kişiliğe Mutluluk. İstanbul: Altın Kitaplar Yayınevi.

Kuyumcu, B. (2012). Üniversite Öğrencilerinin Duygularını Fark Etmeleri Ve ifade Etmeleri Ile Psikolojik Iyi Oluş/arı: Kültürlerarası Bir Karşılaştırma. Yayınlanmamış Doktora Tezi. Gazi Üniversitesi, Eğitim Bilimleri Enstitüsü, Ankara.

Kuzucu, Y. (2011). Duyguları Ifade Etme Ölçeği'nin Uyarlanması: Geçerlik ve Güvenirlik Çalışması. Kastamonu Eğitim Dergisi, 19(3), 779-792.

Lundh, L. G., Johnsson, A., Sundqvist, K. ve Olsson, H. (2002). Alexithymia, Memory of Emotion, Emotional Awareness, and Perfectionism. Emotion, 2(4), 361-379.

Merrell, R. S., Hannah, D. J., Van Arsdale, A. C., Buman, M. P. ve Rice, K. G. (2011). Emergent themes in the writing of perfectionists: A qualitative study. Psychotherapy Research, 21(5), 510-524.

Mete Otlu, B., Ikiz, F., E. ve Asıcl, E. (2016). Duyguları Fark Etme ve ifade Etme Psiko-Eğitim Programının Psikolojik Danışman Adaylarının Öz-duyarlık Düzeyine Etkisi. Elektronik Sosyal Bilimler Dergisi, 15(56), 273-283.

Nyland, J. E. (2004). Dysfunctional Cognitions: Associations with Perfectionistic Thinking Utilizing the Positive and Negative Perfectionism Construct. McNair Scholars Journal, 8(1), 61-67.

Öksüz, Y. (2012). The Impact of Emotional Disclosure Training on Emotional Expression of University Students. The Journal of Academic Sociol Science Studies, 5(2), 421-438.

Pacht, A. R. (1984). Reflections on Perfection. American Psychologist, 39(4), 386-390.

Parker, W. D. (2000). Healthy Perfectionism in the Gifted. Journal of Secondary Gifted Education, 11(4), 173-182.

Parrot, W. G. (2001). Emotional in Social Psychology: Volume Overwiew. In W. G. Parrot (Ed.), Emotions in Social Psychology PA: Psychology Press.

Rafaeli, E., Bernstein, D. ve Young, J. (2013). Şema Terapi Ayırıcı Özellikleri, (2. b.). (A. Karaosmanoğlu, N. Azizlerli, Dü, and M. Şaşığlu, Çev.) İstanbul: Psikonet Yayınları.

Rice, K. G., Tucker, C. M. ve Desmond, F. F. (2008). Perfectionism and Depression Among LowIncome Chronically III African American and White Adolescents and Their Maternal Parent. Journal of Clinical Psychology Medical Settings, 15(3), 171-181.

Serim, F. (2011). Yetişkinlerin Psikolojik Yardım Arama Tutumlarının Yordanması. Yayınlanmamış Yüksek Lisans Tezi, Ege Üniversitesi, Sosyal Bilimler Enstitüsü, İzmir.

Shafran, R., Egan, S. ve Wade, T. (2010). Overcoming Perfectionism. Constable and Robinson Limited: Londra.

Sharf, R. S. (2014). Psikoterapi ve Psikolojik Danışma Kuramları Kavramlar ve Örenek Olaylar, (5.b.). (N. V. Acar, Dü.) Ankara: Nobel Yayınları.

Smith, M. M., Saklofske, D. H. ve Nordstokke, D. W. (2014). The Link Between Neuroticism and Perfectionistic Concerns: The Mediating Effect of Trait Emotional Intelligence. Personality and Individual Differences, 61(62), 97-100.

Smyth, J. M., Pennebaker, J. W. ve Arigo, D. (2001). What Are the Health Effects of Disclosure? In T. Revenson, A. Baum, and P.C. Chaoprang (Eds), Handbook of Health Psychology. New York: Taylor and Francis.

Tabachnick, B. G. ve Fidell, L. S. (2013). Using Multivariate Statistics, (6 $6^{\text {th }}$ ed.). Boston: Pearson.

Türkçapar, H. (2012). Bilişsel Terapi, (6.b.). Ankara: HYB Yayıncılık.

Wilson, C., Bushnell, J., Rickwood., D. J., Caputi, P. ve Thomas, S. J. (2011). The Role of Problem Orientation and Cognitive Distortions in Depression and Anxiety Interventions for Young Adults. Advances in Mental Health, 10(1), 52-61. 
Yalçın, S. B. (2010). Üniversite Öğrencilerinin Duyguları ifade Edebilmelerinin Aleksitimi Ve Psikolojik intiyaçlarına Göre Incelenmesi. Yayınlanmamış Doktora Tezi. Selçuk Üniversitesi, Eğitim Bilimleri Enstitüsü, Konya.

Yalçın, S. B., Ak, M., Kavaklı, M. ve Kesici, ş. (2018). Mutluluğun önündeki engel: Erken dönem uyumsuz şemalar. Journal of Cognitive-Behavioral Psychotheraphy and Research, 7(1), 7-13.

Yalçın, S. B., Kavaklı, M. ve Kesici, Ş. (2017). The Predictive Power of Undergraduates' Personality Traits and Self-Esteem Regarding Their Forgiveness. Journal of Education and Practice, 8(18), 1320.

Yalçın, S. B., Kavaklı, M., Kesici, Ş. ve Ak, M. (2017). University Students' Early Maladaptive Schemas' Prediction of Their Mindfulness Levels. Journal of Education and Practice, 8(20), 174-181

Young, J. ve Klosko, J. (2013). Hayatı Yeniden Keşfedin, (3.b.). (Çev. S. Kohen ve D. Güler,) İstanbul: Psikonet Yayınları.

Young, J., Kolosko, J. ve Weishaar, M. (2009). Şema Terapi. (Çev. T. V. Soylu) İstanbul: Litera Yayıncılık. 


\section{Extended Summary}

Perfectionism is individual's setting down self-challenging standards, overtrying to attain these preset standards despite the problems caused and presenting a self-criticizing attitude via depending their self-worth on high standards (Shafran, Egan and Wade,2010). Perfectionism was found to be analysed as a one-dimensional and multi-dimensional structure. One dimensional perspective merely focused on the negative aspects of perfectionism and assumed perfectionism as a maladaptive personality trait (Pacht, 1984; Adler, 2000; Horney, 1995; Burns, 2012). The ones who categorized perfectionism as a two-dimensional personality trait claimed that perfectionism is not only a negative trait but also a positive one that motivates individuals for achievement and improves a low level of self-criticism due to high standards (Parker, 2000; Rice, Tucker and Desmond, 2008; Hamachek, 1978). Hewitt and Flett (1991) described three dimensions of perfectionism. Self-oriented perfectionists tend to set unrealistic and farfetched personal standards accompanied with high level of self-criticism and lack of tolerance towards any faults. Other-oriented perfectionists tend to have high expectations from the others. Other-oriented perfectionists are not generally willing to give any responsibilities to the others due to the fear of disappointment caused by the others' possible imperfect behaviors. Socially prescribed perfectionists believe that other people have got impossible expectations from them to achieve (Hewitt and Flett, 1991).

It is very significant for the perfectionist individuals to attain self-awareness and to obtain the essential knowledge and ability to overcome their perfectionist attitudes by presenting them these abilities so as to make individuals achieve personal satisfaction. It is expected that the results found in this study will enlighten researchers in psychological counseling and guidance who work with perfectionist individuals.

\section{Purpose}

This study is considered to bring a different perspective to perfectionism having a significant impact on individuals' lives, to enlighten further studies and also to make a contribution to the field and to the introductive programs related to perfectionism that will be developed in the future. Thus, the aim of this study to find out how much variance in university students' perfectionism by their cognitive errors and emotional expression levels and also to find whether there is a significant relationship between their cognitive errors, emotional expression and their perfectionistic attitude.

\section{Method}

The study group consisted of 458 university students studying in the Ahmet Keleşoğlu Faculty of Education at Necmettin Erbakan University. "Frost Multidimensional Perfectionism Scale", "Emotional Expression Questionnaire" and "The Cognitive Errors Questionnaire" were used to gather the data for the study.

\section{Results}

According to the research results, there is significant positive relationship between the expression of positive emotion and parental expectations, doubts about actions whereas there is a negative relationship between the expression of positive emotion and organization. Furthermore, there is a significant negative correlation between the expression of intimacy and parental criticism. Catastrophizing, overgeneralization, personalization and selective abstraction positively correlate with concern over mistakes, parental criticism and doubts about actions. A significant positive correlation was found between catastrophizing, overgeneralization, personalization and parental expectations. Moreover, there is a significant positive correlation between catastrophizing, personalization and personal standards. According to the hierarchical regression analysis, the expression of positive emotion was found to be a significant predictor of organization, parental expectations and doubts about actions which are the subscales of perfectionism. On the other hand, the expression of intimacy is significant predictor of parental criticism. While catastrophizing 
and personalization are the significant predictors of concern over mistakes, personalization was found to be a significant predictor of personal standards. Overgeneralization was found to be a significant predictor of parental expectations, whereas overgeneralization and personalization were found to be significant predictors of parental criticism. Lastly, catastrophizing and personalization are significant predictors of doubts about actions.

\section{Discussion and Conclusion}

Based on the findings of this study, the expression of positive emotion correlates negatively with organization while the expression of intimacy correlates with parental criticism in the same direction. Moreover, the expression of positive emotion was found to be a significant predictor of organization and the expression of intimacy is a significant predictor of parental criticism as well. According to these results, it might be claimed that university students' compulsive desires for cleanliness, organization and order will decrease, as the level of using the expression of positive emotion increases. It can be stated that students acting with the expression of intimacy have got low level of parental criticism. Upon exploring the other variables related to perfectionism in the other studies, it was found that the level of preoccupation with cleanliness, organization and order decreases as the expression of positive emotion level increases, which is similar to the results of this study. Examining the research results intensely, it was found that perfectionist are the individuals with a low level of self-consciousness and self-control whose empathic tendency is weak and emotional expression is insufficient. Furthermore, perfectionist individuals tend to suppress their emotions as they have low emotional regulation skills.

When perfectionist individuals' avoiding to reveal their emotions (Ben-Sharar, 2014), and also individuals with excessive self-criticism trying to cover up their personal problems (Kawamura and Frost, 2004; Frost, et. al., 1997; Frost, et al., 1995) were taken into consideration, there is not a consistency with the other related studies, since in this study correlation was found between the expression of positive emotions and parental expectations and also between the expression of positive emotions and doubts about actions.

The current study findings have similar results with the researches which were held before. According to findings of this study, it was determined that perfectionist individuals have negative cognitive structures. Flett, Hewitt, Blankstein andGrey (1998) stated that perfectionism cognition positively correlates with defining high standards to reach, overgeneralization, self-criticism and concern over mistakes. The correlation between cognitive errors and perfectionism can be clearly realized since perfectionists individuals are the ones who consider themselves as underachievers when they cannot attain their preset strict standards, label themselves as a total failure just for one fault, focus on only negative aspects of their performance by ignoring the positive ones, tend to interpret a failure as catastrophe by taking the whole responsibility of that action on their shoulders (Shafran, Egan, and Wade, 2010; Antony \&Swinson, 2000; Ben-Shahar, 2014; Barrow and Moore,1983) and also the ones who have unrealistic thoughts such as setting high and strict standards, having a tendency to see themselves insufficient to attain this standards, being anxious about their skills (Enns, Cox and Clara, 2002). As a conclusion, it can be inferred that the university students' perfectionist's attitudes can be diminished by reducing their cognitive errors. 